\title{
CONTRIBUIÇÕES DA LÍNGUA PORTUGUESA PARA UMA PROPOSTA DE LETRAMENTO CIENTÍFICO E TECNOLÓGICO NO CONTEXTO ESCOLAR
}

\author{
Aline Diesel, Eniz Conceição Oliveira, José Claudio Del Pino, Diorge Jônatas Marmit \\ Centro Universitário UNIVATES \\ Lajeado, Rio Grande do Sul \\ E-mail: aline.diesel@hotmail.com, eniz@univates.br, jose.pino@univates.br, diorgemarmitt@yahoo.com.br
}

Resumo: Este artigo, que parte de uma revisão bibliográfica, trata do enfoque curricular em Ciência, Tecnologia e Sociedade (CTS), o que significa trabalhar conteúdos que preparem o aluno para ser um cidadão crítico, capaz de compreender os problemas da sociedade, sabendo agir sobre eles. O objetivo desse trabalho foi evidenciar as contribuições da disciplina Língua Portuguesa no contexto de uma abordagem em CTS. Além disso, é apresentada uma proposição de atividade didática criada a partir da obra "O menino do dedo verde", de Maurice Druon, que instigam os alunos a interferirem na realidade local, promovendo melhorias. Foram utilizados os pressupostos teóricos de Santos (2007), Del Pino e Frizon (2011) e Antunes (2009), entre outros. Como resultado principal, averiguou-se que a disciplina Língua Portuguesa pode contribuir significativamente nesse processo quando tem seu trabalho voltado em favor da leitura.

Palavras-chave: CTS. proposta de atividade. língua portuguesa.

\section{CONTRIBUTIONS OF THE PORTUGUESE LANGUAGE FOR A SCIENTIFIC AND TECHNOLOGICAL PROPOSAL OF LITERACY IN THE SCHOOL CONTEXT}

\begin{abstract}
This article originated from a bibliographical revision and covers the curricular focus on Science, Technology and Society (STS), which means to work on contents that would prepare students to be critical citizens who are capable of understanding society's problems and know how to act upon them. The objective of this paper is to bring to evidence the contributions of the Portuguese Language subject towards the context of an STS-based approach. Additionally, a proposition is presented for a didactic activity created from Maurice Druon's work "The boy with green thumbs" that instigates students to interfere with local reality to promote improvements. The theoretical presumptions by Santos (2007), Del Pino \& Frizon (2011) and Antunes (2009), among others, were employed. The main result led to verify that the Portuguese Language subject may contribute significantly with this process when it is worked on in favor of reading.
\end{abstract}

Keywords: STS. activity proposal. Portuguese Language.

Recebido em 27/01/2016. Publicado em 30/06/2016. 


\section{INTRODUÇÃO}

A ciência e a tecnologia influenciam cada vez mais na qualidade de vida, especialmente no que diz respeito à alimentação, saúde, cultura, educação. As pesquisas científicas aliadas a avanços tecnológicos desenvolvem constantemente alimentos mais saudáveis, tecnologia avançada para tratar e curar enfermidades, criam artifícios para evitarmos a poluição, entre tantos outros benefícios.

Dentro desse panorama, existe um trabalho transdisciplinar em que diferentes profissionais dialogam para buscar resolver grandes dilemas sociais, como a cura da aids, a escassez de alimentos, problemas ambientais, entre outros (SANTOS; MORTIMER, 2002).

Dessa feita, o mundo contemporâneo exige cidadãos preparados para a ciência e a tecnologia, capazes de compreender os desafios do mundo e de tomar decisões favoráveis a ele (SANTOS; MORTIMER, 2002). A escola precisa estar atenta a essa realidade e preparar um sujeito comprometido efetivamente com o ambiente no qual está inserido.

Essa abordagem não é recente. A Constituição Federal já previu que a educação fosse direcionada para o preparo da cidadania (BRASIL,1988). Ligado a isso, os Parâmetros Curriculares Nacionais de Língua Portuguesa preveem a necessidade de desenvolver a "competência discursiva para falar, escutar, ler e escrever nas diversas situações de interação" (BRASIL, 1998, p. 34).

Embora rodeados de diretrizes que direcionem o ensino para o aluno há quase 30 anos, o que ainda vemos muito são aulas baseadas em cópia, memorização, exercícios com conteúdos sem nenhum valor para o aluno. Se considerarmos o ensino da Língua Portuguesa, veremos aulas direcionadas para a memorização de regras gramaticais, sendo o texto (basicamente narrativo) trazido para a sala de aula apenas com o propósito de abordagem dessas regras. É o que pautua Tiepolo (2014, p.35):

O ensino de conteúdos enciclopédicos e descontextualizados por vezes acontece de forma verbalista e ensinar é sinônimo de repassar conteúdos. A ênfase está na resolução de exercícios, cópias e leituras e na repetição e memorização de conceitos e fórmulas, existindo, além disso, um estímulo para o individualismo.

Para mudar esse quadro da educação brasileira, surgiu uma corrente que defende o direcionamento dos currículos das escolas para a Ciência, Tecnologia e Sociedade (CTS), o que 
significa trabalhar nas salas de aula as "inter-relações entre explicação científica, planejamento tecnológico, solução de problemas, e tomada de decisão sobre temas práticos de importância social" (SANTOS; MORTIMER, 2002, p. 3), incluindo valores éticos e princípios democráticos. Dessa forma, a escola promoverá o Letramento Científico e Tecnológico (LCT), ou seja, a formação de cidadãos que não só serão capazes de compreender os problemas políticos, ambientais, sociais, econômicos enfrentados pelo mundo, como também estarão preparados para enfrenta-los, pois terão uma visão crítica e comprometida com a sociedade.

Na perspectiva da formação para a cidadania e a tomada de decisão, o ensino numa proposta fundamentada na tríade CTS, significa o ensino do conteúdo de ciência no contexto autêntico do seu meio tecnológico e social. Os estudantes tendem a integrar sua compreensão pessoal do mundo natural (conteúdo da ciência) com o mundo construído pelo homem (tecnologia) e o seu mundo social do dia a dia (sociedade) (SANTOS; SCHNETZLER, 1997, p.1).

Nessa visão, o aluno deve finalizar a educação básica com conhecimentos, habilidades e valores necessários para tomar decisões responsáveis sobre questões de ciência e tecnologia, contribuindo para a solução dessas questões, se for o caso (SANTOS; MORTIMER, 2002). Dentre esses conhecimentos e habilidades, temos:

a autoestima, a comunicação escrita e oral, o pensamento lógico e racional para solucionar problemas, a tomada de decisão, a aprendizado colaborativo/cooperativo, a responsabilidade social, o exercício da cidadania, a flexibilidade cognitiva e o interesse em atuar em questões sociais (SANTOS; MORTIMER, 2002, p. 5).

Pelas inúmeras contribuições da abordagem CTS para a sociedade, acredita-se que ela precisa urgentemente ser introduzida no âmbito da escola, tornando-se familiarizada para os professores, que são os principais agentes provocadores das escolas. São eles que devem trazer práticas pedagógicas inovadoras e proporcionar aulas com esse enfoque aos alunos. Acredita-se que os professores percebam essa importância, entretanto esbarram num cotidiano com muita carga horária de trabalho, falta de tempo para preparo de aulas, deficiência na formação inicial e continuada, falta de apoio pedagógico, e, por que não dizer, falta de entusiasmo e motivação em algumas situações. 
Numa pesquisa exploratória sobre CTS em portais de periódicos, tem-se muitos exemplos de atividades desenvolvidas em sala de aula que objetivaram a preparação do cidadão crítico e comprometido com a sociedade. De uma forma geral, percebe-se que a concepção que se tem sobre abordagem CTS em sala de aula está muito direcionada para o ensino de Ciências, especialmente nas disciplinas de Química, Física, Matemática e Biologia, como se pode ver nos conteúdos que, de acordo com Santos e Schnetzler (1997), contemplam o letramento científica por meio do ensino CTS: saúde; alimentação e agricultura; recursos energéticos; terra, água e recursos minerais; indústria e tecnologia; ambiente; transferência de informação e tecnologia; ética e responsabilidade social; qualidade do ar e atmosfera; fome mundial e fontes de alimentos; guerra tecnológica; crescimento populacional; recursos hídricos; falta de energia; substâncias perigosas; saúde humana e doença; uso da terra; reatores nucleares; animais e plantas em extinção. São conteúdos que estão, de alguma forma, contemplados nos currículos das disciplinas das áreas das Ciências Naturais e Exatas.

Diante do exposto, deparamo-nos com as seguintes questões, que nortearam e motivaram este estudo: prepara-se o aluno para ser cidadão crítico e capaz de tomar decisões responsáveis apenas nas disciplinas de Ciências, Química, Física, Matemática, Biologia? Somente essas disciplinas promovem o letramento científico e tecnológico? Ao preparar o aluno para ler criticamente os mais diversos gêneros textuais, será que não estamos contribuindo nessa linha também?

Assim, pretende-se, neste trabalho, apresentar alguns pressupostos teóricos e práticos que evidenciam que a disciplina de Língua Portuguesa pode contribuir significativamente, e de fato contribui, para formar um cidadão preparado para compreender o mundo em que vive, capaz de refletir sobre ele e agir ativamente para poder contribuir para o seu progresso. É importante ter presente que a proposição da organização do currículo escolar na vertente teórica de CTS, parte da compreensão da necessidade da integração das áreas de conhecimento, das linguagens, da matemática, das ciências naturais e das ciências humanas. Em razão disso, acredita-se também que o desenvolvimento da habilidade da leitura não deve acontecer unicamente nas aulas de Língua Portuguesa:

Ler e escrever são tarefas da escola, questões para todas as áreas, uma vez que são habilidades indispensáveis para a formação de um estudante, que é responsabilidade da escola. [...]. Ensinar é ensinar a ler para que o aluno se torne 
capaz dessa apropriação, pois o conhecimento acumulado está escrito em livros, revistas, jornais, relatórios, arquivos. Ensinar é ensinar a escrever porque a reflexão sobre a produção de conhecimento se expressa por escrito (GUEDES; SOUZA, 2000, p. 13).

Cabe salientar que este estudo originou-se de reflexões promovidas na disciplina "Fundamentos de Alfabetização Científica e Tecnológica", ministrada no Mestrado do Programa de Pós-Graduação em Ensino, de um Centro Universitário, situado do Vale do Taquari-RS, em janeiro de 2015.

Nesse intuito, a partir de uma pesquisa bibliográfica, que tem um enfoque teórico sobre o estado da arte no tema em discussão, apresentam-se, inicialmente, aspectos relacionados ao letramento científico. A seguir, trazem-se apontamentos pautados por estudiosos da área da linguagem que fundamentam a abordagem CTS nas aulas de Língua Portuguesa.

$\mathrm{Na}$ sequência, é apresentada uma unidade didática com práticas pedagógicas inovadoras elaboradas a partir da obra "O menino do dedo verde", de Maurice Druon, que podem instigar os alunos a interferirem na realidade local. Além disso, a unidade poderá servir de inspiração para encorajar professores a desenvolverem novas ideias a partir delas.

\section{O LETRAMENTO CIENTÍFICO E TECNOLÓGICO}

O letramento científico e tecnológico ultrapassa a simples conquista das competências em decifração dos sinais da escrita. Del Pino e Frizon (2011) defendem que o processo de letramento envolve a preparação do cidadão para ser capaz de ler o mundo fazendo julgamentos críticos e políticos. Assim, o letramento dos cidadãos vai desde compreender os princípios básicos de fenômenos do cotidiano até a capacidade de tomada de decisão em questões específicas da ciência e tecnologia em que estejam diretamente envolvidos, sejam decisões pessoais ou de interesse público. Nesse sentido, tem-se ainda:

Letramento em ciência e tecnologia para cidadania, então, incorpora conhecimentos e competências que habilitam o cidadão a tomar decisões pessoais que usem critérios com base em conhecimentos científicos, como por ex., na decisão sobre compra e utilização de novos equipamentos ou até mesmo sobre um tratamento médico, após ouvir diferentes especialistas (DEL PINO; FRIZON, 2011, p. 38). 
Antunes (2009) corrobora com o entendimento anterior. Para ela, a evolução do estágio de alfabetizados para letrados ocorre quando os estudantes veem, ouvem ou manuseiam diferentes suportes de escrita (livros, jornais, folhetos, anúncios, avisos etc.). Além disso,

[...] esse estado vai-se afirmando, vai-se ampliando, continuamente, de maneira que, em estado de letramento, estamos nós todos, a vida inteira. Assim, entre escrita, leitura e escola se estabelece uma vinculação de interdependência tão forte que qualquer uma das três, necessariamente, leva às outras (ANTUNES, 2009, p.192).

Outro ponto, sobre o qual encontramos amparo na reflexão de Santos (2007), diz respeito ao modo como letramento científico reivindica abordagens metodológicas contextualizadas com aspectos sócio-científicos, fazendo uso da leitura de textos científicos que permitam o entendimento das relações ciência-tecnologia-sociedade, o que possibilita a tomada de decisões pessoais e coletivas. Nesse sentido, percebe-se que a escola é responsável pela alfabetização e, sobretudo, pelo letramento do seu aluno. Isso significa, em suma, que a escola tem a responsabilidade imediata por preparar o aluno para ler o mundo, conhecê-lo e preparar sujeitos capazes de agir sobre ele, inovando, e efetivamente, transformá-lo.

Essa não é uma proposta nova, como já mencionamos anteriormente. Entretanto, acredita-se que, para que haja uma transformação na sociedade, é preciso transformar antes a escola. É preciso estimular os professores a desenvolverem práticas pedagógicas inovadoras que tenham o foco no aluno.

Nessa linha, uma das formas de provocar essa mudança na escola, de acordo com Freire e Faundez (1985 p. 46), seria estimular permanentemente a curiosidade, e, sobretudo, o ato de perguntar, o qual jamais deve ser reprimido. De acordo com os autores, a partir de perguntas é que se deve ir em busca de respostas:

A curiosidade do estudante às vezes pode abalar a certeza do professor. Por isso é que, ao limitar a curiosidade do aluno, a sua expressividade, o professor autoritário limita a sua também. Muitas vezes, por outro lado, a pergunta que o aluno, livre para fazê-la, faz sobre um tema, pode colocar ao professor um ângulo 
diferente, do qual Ihe será possível aprofundar mais tarde uma reflexão mais crítica (FREIRE; FAUNDEZ, 1985, p. 44).

O fato é que essa curiosidade precisa ser estimulada e exercitada em sala de aula para que seja levada para a vida, o que poderá transformar o estudante questionador em um cidadão questionador, que não se conforma com o que lhe é imposto. Esse é o papel da escola: estimular o senso crítico do aluno por meio de múltiplas atividades de análise e de reflexão; instigar a "curiosidade, a procura a pesquisa, a vontade da descoberta, o que implica a não conformação com o que já está estabelecido; desestimulando, portanto, o simplismo e o dogmatismo com que as questões linguísticas têm sido tratadas" (ANTUNES, 2009, p.43).

Com essa perspectiva, pode-se afirmar um "currículo que tenha a perspectiva de letramento científico implica a ressignificação dos saberes científicos escolares que estão sendo abordados de forma descontextualizada" (SANTOS, 2007, p. 485). Enquanto não se estiver caminhando nessa direção, a educação formal continuará atrelada à aprendizagem mecânica por meio da transmissão tradicional de conteúdos.

\section{A LÍNGUA PORTUGUESA NA PERSPECTIVA CTS}

Tendo sido feito uma introdução sobre o que seja o ensino pautado em CTS e apresentadas as contribuições desse para a sociedade atual, pretende-se, nesta seção, mostrar como o professor pode promover a formação do cidadão no âmbito mais específico do ensino de línguas.

Uma das principais formas de promover o Letramento Científico e Tecnológico, se não o principal, é a leitura.

Entretanto, essa leitura, muitas vezes, é abordada de forma errônea nas aulas de Língua Portuguesa. Para Kleiman (2002), os livros didáticos estão cheios de exemplos em que o texto é visto como um conjunto de palavras cujos significados devem ser extraídos um por um (substantivo, adjetivo, verbo, etc). Ele serve, muitas vezes, apenas de pretexto para o ensino de regras gramaticais.

Perini (2000) defende o estudo da gramática em sala de aula, entretanto, um estudo que contribua no desenvolvimento de habilidades de aprender por si mesmo, criticar e criar novo 
conhecimento. Para o autor, a gramática deve ser um instrumento de descoberta, de exercitar o raciocínio e a observação, oportunizando formular e testar as hipóteses.

[...] as habilidades de raciocínio, de observação, de formulação e testagem de hipóteses [...] são um pré-requisito à formação de indivíduos capazes de aprender por si mesmos, criticar o que aprendem e criar conhecimento novo. [...] se há algo que nossos alunos em geral não desenvolvem durante a sua vida escolar é exatamente a independência de pensamento. $O$ estudante brasileiro (e, muitas vezes, também o professor) é tipicamente dependente, submisso à autoridade acadêmica, convencido de que a verdade se encontra, pronta e acabada, nos livro e na cabeça das sumidades. Daí, em parte, a perniciosa ideia de que a educação é antes de tudo transmissão de conhecimento, quando deveria ser em primeiro lugar procura de conhecimento e desenvolvimento de habilidades (PERINI, 2000, p.31, grifo nosso).

Como se percebe, devemos e podemos promover práticas na escola em favor da leitura que provoque a capacidade de pensar. O aluno deve sentir que está participando desse ato de descoberta, através de sua contribuição à discussão, ao argumento, à procura de novos exemplos e contraexemplos cruciais para a testagem de uma hipótese da gramática. Assim, a escola estará contribuindo:

por políticas educacionais que priorizem a ampliação das competências relevantes para o pleno exercício da cidadania. Pela intervenção de uma escola que ponha a produção do conhecimento relevante e o acesso a ele no centro de seus objetivos, de sua atividade. Que priorize a ampliação das competências das pessoas, para que possam intervir, positivamente, na direção do bem coletivo. Concretamente que tenha livros e leitores desses livros com tempo e vez para saber o que esses livros dizem. Tudo isto, para que possamos nos aproximar sempre mais da solução dos grandes problemas humanos. Pela ação não menos consistente de uma sociedade que se sinta no legítimo direito de contar com uma escola na qual, pelo exercício pleno da leitura, se aprenda também a pensar, a expressar-se, a participar, na condição de cidadão, das decisões da comunidade e a interferir no seu destino (ANTUNES, 2009, p.205). 
Diante das considerações feitas até aqui, considera-se pertinente apresentar uma unidade didática voltada para a Língua Portuguesa que prepare para o exercício da cidadania.

A proposta aqui apresentada poderá ser desenvolvida com turmas do terceiro ao sexto ano do Ensino Fundamental, dependendo da maturidade dos alunos. Cabe ao professor julgar e sentir-se seguro para aplicar a atividade. Da mesma forma, as atividades aqui propostas não são engessadas, podendo ser adaptadas pelos professores de acordo com sua realidade, tempo disponível e objetivo.

O trabalho tem como tema a melhoria da qualidade de vida a partir de um projeto de leitura da obra O menino do dedo verde (DRUON, 1982), tendo como objetivo principal interferir na realidade local, promovendo melhorias a partir da leitura de uma obra literária, tendo em vista a formação de um cidadão questionador, crítico, inovador. Além disso, o projeto objetiva também incentivar o gosto pela leitura; desenvolver a oralidade do aluno; conhecer elementos essenciais de diferentes gêneros textuais (texto literário, ofício, rifa, notícia). O projeto de leitura pode ser realizado em várias etapas:

\subsection{Primeira etapa - aquisição das obras}

Se a proposta for desenvolvida numa realidade de periferia, na qual os alunos não têm possibilidade financeira de aquisição do livro, sugere-se outra forma de iniciar o projeto: os alunos são desafiados a organizarem uma rifa, na qual eles próprios devem redigir ofício para os estabelecimentos comerciais solicitando a doação de mercadoria que será o prêmio da rifa. Tendo feito isso, devem estipular as normas para o melhor funcionamento da rifa e organizar as cartelas que deverão ser vendidas por eles mesmos. Com o dinheiro arrecadado, são adquiridos os livros.

Salienta-se, nesse processo, a importância do papel do professor de estimular e auxiliar os estudantes. Entretanto, deve ficar claro que são os alunos que farão o trabalho, cabendo ao docente apenas a função de auxílio.

As obras também podem ser adquiridas pelos alunos, caso não haja disponibilidade para a organização da rifa. 


\subsection{Segunda etapa - leitura da obra}

Nessa proposta, é necessário que cada aluno tenha o livro. A leitura pode acontecer utilizando diversas estratégias: leitura individual em casa (o professor delimita a extensão da leitura); leitura em duplas, em sala de aula (um aluno lê para o outro); leitura em grande grupo, na sala de aula.

Durante a leitura, o professor deve averiguar a compreensão de elementos essenciais da história, por meio de questionamentos orais. Além disso, deve provocar os alunos a elaborarem previsões e hipóteses quanto à continuação da história, o que aguça a curiosidade dos alunos e motiva-os a continuarem lendo.

\subsection{Terceira etapa}

Tendo concluído a leitura do livro, é feita uma socialização da história, observando os elementos que constituem o enredo: foco narrativo, caracterização dos personagens, espaço, tempo.

Nesse processo, é importante que o professor desenvolva atividades práticas e dinâmicas. Se trouxer uma folha dizendo "escreva qual o foco narrativo da história" ou "quais são as personagens principais", quebra-se o encanto da história. Estará cometendo um atentado ainda maior se disser que irá recolher a folha ao final da aula para avaliação semestral. É o que muitas vezes acontece nas aulas de Língua Portuguesa e, acredita-se, é a causa de muitos alunos serem aversão à leitura.

\subsection{Quarta etapa}

Os alunos devem deslocar-se até a biblioteca da escola e analisar as notícias do(s) jornal(is) da sua cidade. Em grupos, a partir da análise desses jornais, os alunos são desafiados a identificarem os problemas na sua cidade, registrando-os no caderno (por exemplo: problemas de trânsito, ambientais, etc.). Então, baseados no livro "O menino do Dedo Verde", os alunos devem produzir uma história em que "Tistu" agiria sobre esse local da cidade do aluno identificado como problemático.

\subsection{Quinta etapa}


A professora organiza uma visita ao(s) local(is) identificados como problemáticos pelos alunos. Nessa visita, devem, em grupo, refletir sobre e elaborar sugestões de contribuição para os problemas elencados.

\subsection{Sexta etapa}

Como encerramento da atividade, sugere-se a escrita uma carta em conjunto (toda a turma), direcionada para os responsáveis pelo(s) local(is) para proposição de sugestões. Caso seja identificada como problemática uma indústria, a carta será direcionada para o dono ou presidente; o local foi algo relacionado ao trânsito, a carta será encaminhada ao prefeito da cidade; etc. O destinatário da carta poderá ser convidado para visitar os alunos na escola e comentar as proposições da turma.

Com essa proposta, os alunos dos anos iniciais do Ensino Fundamental já serão instruídos, desde ainda muito jovens, a um olhar crítico do local onde estão inseridos. A partir disso, saem da zona de conforto de apenas reclamar, e partem para a ação. Tomam a frente para tentar solucionar o problema com o qual se depararam. Acredita-se que promover atividades nesse formato em sala de aula, durante toda a educação básica e em todas as disciplinas, formará agentes de Letramento Científico e Tecnológico.

\section{CONSIDERAÇÕES FINAIS}

É indispensável, hoje, que o ensino tenha enfoque em CTS, o que significa abordar temas que de fato poderão contribuir para um sujeito letrado cientificamente, ou seja, um sujeito mais ativo e crítico na sociedade, capaz não só de compreender a sociedade, mas reconhecer seu papel como participante de decisões.

A escola deve oferecer condições para que a cultura científica seja conhecida e vivenciada pelos alunos, para que, dessa maneira, possam construir conceitos, desenvolvendo habilidades de pensamento, de julgamento e tomada de decisões. Portanto, é primordial desenvolver práticas pedagógicas inovadoras como as apresentadas aqui, que tenham o foco no aluno, de modo a estimular-Ihe a curiosidade. 
A Língua Portuguesa pode contribuir significativamente nesse processo quando tem seu trabalho voltado em favor da leitura, de modo que instiga a pensar, a expressar-se, a participar, na condição de cidadão, das decisões da comunidade e a interferir no seu destino.

A proposta de atividade apresentada contribuiu para desenvolver essas habilidades. De forma alguma pode ser vista como utópica, pois de fato pode ser desenvolvida em sala de aula. Para tal, é necessário um professor corajoso, disposto com um ensino pautado nos princípios da CTS.

Salienta-se, também, que as ações descritas neste trabalho devem ser adequadas para cada realidade, podendo ser acrescentados novas atividades. Evidentemente é possível também suprimir ações ou mesmo substituir ações por outras. O importante é que o trabalho torne-se prazeroso e que haja a construção do conhecimento.

\section{REFERÊNCIAS}

ANTUNES, Irandé. Língua, texto e ensino: outra escola possível. São Paulo: Parábola Editorial, 2009.

BRASIL. Constituição da República Federativa do Brasil. Brasília, DF: Senado Federal: Centro Gráfico, 1988. Disponível em: <planalto.gov.br/ccivil_03/constituicao/constituicaocompilado.htm>Acesso em: 11 fev. 2015.

BRASIL. Secretaria de Educação Fundamental. Parâmetros curriculares nacionais: terceiro e quarto ciclos do ensino fundamental (Língua Portuguesa). Secretaria de Educação Fundamental - Brasília: MEC/SEF, 1998. Disponível em: <portal.mec.gov.br/seb/arquivos/pdf/portugues.pdf> Acesso em: 11 fev. 2015.

DEL PINO, José Claudio; FRISON, Marli Dallagnol. Química: Um Conhecimento Científico para a Formação do Cidadão. Revista de Educação, Ciências e Matemática. v. 1, n. 1, ago/dez. 2011. Disponível em: <publicacoes.unigranrio.edu.br/index.php/recm/article/viewFile/1585/769>. Acesso em: 10 fev. 2015.

DRUON, Maurice. O menino do dedo verde. Rio de Janeiro: José Olympio, 1982.

FREIRE, Paulo; FAUNDEZ, Antonio. Por uma pedagogia da pergunta. Rio de Janeiro: Paz e Terra, 1985.

GUEDES, Paulo Coimbra; SOUZA, Jane Mari de. Leitura e escrita são tarefas da escola e não só do professor de português. In: NEVES, lara Conceição Bitencourt et al. (Org.). Ler e escrever: compromisso de todas as áreas. Porto Alegre: UFRGS, 2006.

KLEIMANN, Angela. Oficina de leitura: teoria e prática. Campinas: UNICAMP, 1993.

PERINI, Mário Alberto. Gramática descritiva do português. São Paulo: Ática, 2000.

TIEPOLO, Elisiane Vitória. Falar, ler e escrever na escola: práticas metodológicas para o ensino de língua portuguesa. Curitiba: InterSaberes, 2014. E-book.

SANTOS, Wildson dos. SCHNETZLER, Roseli. Educação em química: compromisso com a cidadania. ljuí, Ed.Unijuí, 1997.

SANTOS, Wildson P.; MORTIMER, Eduardo F. Uma Análise de Pressupostos Teóricos da Abordagem CTS (Ciência Tecnologia - Sociedade) no Contexto da Educação Brasileira. Ensaio. Pesquisa em Educação em Ciências. v. 2, n. 2, dez. 2002. 
SANTOS, Wildson Luiz Pereira dos. Educação científica na perspectiva de letramento como prática social: funções, princípios e desafios. Revista Brasileira de Educação. v. 12, n. 36.2007. 